\title{
Survival rate of Saccharomyces boulardii adapted to a functional freeze- dried yogurt: experimental study related to processing, storage and digestion by Wistar rats
}

\author{
${ }^{a}$ Eunice Tranquilino-Rodriguez, ${ }^{b} *$ Hector E. Martinez-Flores, ${ }^{b}$ Jose O. Rodiles-Lopez, \\ ${ }^{b}$ Rafael Zamora-Vega, ${ }^{c}$ Rafael Salgado-Garciglia, ${ }^{\mathrm{d}}$ Rosa E. Perez-Sanchez.
}

${ }^{a}$ Programa Institucional de Maestria en Ciencias Biologicas, Universidad Michoacana de San Nicolas de Hidalgo; ${ }^{b}$ Facultad de Quimico Farmacobiologia, Universidad Michoacana de San Nicolas de Hidalgo; 'Instituto de Investigaciones Quimico Biologicas, Universidad Michoacana de San Nicolas de Hidalgo, Morelia, Mich., Mexico; ${ }^{\mathrm{d}}$ Facultad de Agrobiologia "Presidente Juarez", Universidad Michoacana de San Nicolas de Hidalgo, Uruapan, Mich., Mexico

*Corresponding author: Facultad de Quimico Farmacobiologia. Universidad Michoacana de San Nicolas de Hidalgo. Morelia, Mich., Mexico

Submission Date: December 5, 2016, Acceptance date: February 21, 2017: Publication date: February 28, 2017

Citation: Rodriguez ET, Flores HEM, Lopez JOR, Vega RZ, Garciglia RS, Sanchez REP. Survival rate of Saccharomyces boulardii adapted to a functional freeze-dried yogurt: experimental study related to processing, storage and digestion by Wistar rats. Functional Foods in Health and Disease 2017; 7(2): 98-114

\begin{abstract}
Background: Saccharomyces boulardii is a probiotic clinically effective in the prevention and treatment of antibiotic induced diarrhea in both children and adults, Clostridium difficile infections, inflammatory bowel disease, and other gastrointestinal disorders. However, the microorganisms need to survive the gastrointestinal transit and arrive to their action site alive in order to exert their beneficial effects. Microencapsulation is an alternative to improve the viability of probiotic in foods which can also survive in the gastrointestinal conditions. Freeze-drying is a method of dehydration that does not affect nutrients and bioactive compounds, such as probiotics contained in foods. All of them will increase the survival rate of S. boulardii.
\end{abstract}

Purpose of this study: This study focused on formulae freeze-dried yogurt containing inulin, vegetable palm oil, and $S$. boulardii, both as free cells and in microencapsulated form. Also, the effect of ampicillin associated $S$. boulardii.

Methods. Yogurts were given to an "in vivo" digestion process, using male Wistar rats. The survival of $S$. boulardii was subsequently evaluated in colon and feces. For this study, six treatments of four of rats were used: i) control rats ii) rats fed with yogurt containing S. boulardii as free cells, iii) rats fed with yogurt containing $S$. boulardii in micro-encapsulated form, iv) control rats fed with penicillin, v) rats fed with ampicillin plus yogurt containing $S$. boulardii as 
free cells, and vi) rats fed with penicillin plus yogurt containing S. boulardii in microencapsulated form.

Results: The study demonstrated it was feasible to freeze-dry the $S$. boulardii and incorporate it into a yogurt made with skim milk, inulin, and unsaturated vegetable oil. The freeze-drying process not affected the survival of the $S$. boulardii $(\mathrm{p}<0.05)$. Microencapsulation increased the survival of $S$. boulardii on 1.77-Log CFU/g, and the presence of $S$. boulardii was only detected in colon and feces of those rats which ingested ampicillin, regardless to the formula contained the probiotic.

Conclusion: This study demonstrated that freeze-drying maintains the survival of $S$. boulardii in the evaluated foods and that micro-encapsulation increases the survival of this probiotic. Furthermore, $S$. boulardii was installed in the gastrointestinal tract when the microbial flora was damaged by ampicillin.

Keywords: Yogurt, probiotic, Saccharomyces boulardii, micro-encapsulation, freeze-drying.

\section{INTRODUCTION}

Functional food provides one or more substances that contribute to human health and some of them are found naturally and can prevent ailments and chronic diseases related to diet [1, 2, 3]. These sources include the following: carrots (carotenoids), tomato (lycopene), tea (phenolic compounds), fruit and vegetables (fiber, phytochemicals) [4, 5], vegetable oils (omega-3 and omega-6), and various grains and cereals (fiber, phenol compounds, and phytochemicals). Some research has developed new functional foods based on the study of microorganism probiotics, in order to provide their biological activity and potentially beneficial effects on health particularly as preventive measure for diarrhea, constipation, and treatment of colitis [6].

The term probiotics is derived from a Latin meaning "for life" [7]. The definition accepted by the Food and Agriculture Organization (FAO) and the World Health Organization (WHO), probiotics are "Live microorganisms which, when administered in adequate doses amounts, confer benefit to the health of the host" [8]. Ideal criteria for probiotics are: i) survival of passage through the gastro-intestinal tract, ii) tolerance to acid, bile, gastric enzymes, and iii) adherence and colonization of the intestinal epithelium [9]. Lactobacilli and bifidobacterial strains are the most popular probiotics for human consumption because they improve both health and intestinal symptoms of lactose intolerance, in addition to reducing the risk of other diseases [10]. Yeasts such as Saccharomyces boulardii are also marketed as probiotics [11]. It has been estimated that probiotics comprise between $60 \%$ and $70 \%$ of functional foods currently available on the market [12]. The active mechanism of $S$. boulardii include: regulation of intestinal microbial homeostasis, interference with the ability of pathogens to colonize and infect the mucosa, modulation of local and systemic immune responses, stabilization of the gastro-intestinal barrier, inhibition of pro-carcinogenic enzymes, and finally induction of enzyme activity which promotes the absorption of nutrients [13]. S. boulardii is currently used as a probiotic in the treatment of 
antibiotic induced diarrhea in both children and adults, Clostridium difficile infections, inflammatory bowel disease, and other gastrointestinal disorders [14].

Yogurt is one of the most popular fermented milk products worldwide, as it has many health benefits, including the reduction of lactose intolerance, lowering of the risk of certain types of cancer, anti-cholesterolemic effects, and prevention of genital and urinary tract infections, effects which are combined with other health attributes associated with probiotic bacteria such as: Lactobacillus delbrueckii ssp. bulgaricus and Streptococcus thermophilus [15].

The aim of this study was to know the effect in survival rate of $S$. boulardii prepared as freeze-dried yogurt prepared with skimmed-milk. Palm vegetable oil was added to replace milk fat in order to obtain yogurt with a lower saturated fatty-acid content and to increase polyunsaturated fatty acids, in addition to removing cholesterol from the product. Inulin was used to improve the consistency and texture of the yogurt. Another goal was to use $S$. boulardii, either as free cells or microencapsulated form. The yogurt was freeze-dried as to increase the formerly accepted shelf-life of 21 days [16], facilitate transport (stored at an ambient temperature of $25^{\circ} \mathrm{C}$, 84 days) and rehydrate for consumption. We have characterized the physicochemical, microbiological, and sensory properties of re-hydrated yogurts. The survival of $S$. boulardii in yogurt was measured, not only by the effects of freeze-drying and storage at $25{ }^{\circ} \mathrm{C}$ but also by passage through the gastro-intestinal tract of Wistar rats. Finally, we tested the addition microbial flora, which had been damaged by the addition of ampicillin; yogurt containing $S$. boulardii was also given to the rodents in order to observe its capacity to restore flora to the colon.

\section{MATERIALS AND METHODS}

Milk with $0.2 \%$ fat content. The L. delbrueckii subspecies bulgaricus and S. thermophilus subspecies salvarius (Danisco®) were used. S. boulardii was provided by the Laboratory of Microbiology of the Faculty of Chemical Pharmacobiology (Universidad Michoacana de San Nicolas de Hidalgo). Inulin from the Agave tequilana subspecies weber blue variety and vegetable oil were employed. Inulin (PubChem CID: 24763); Calcium carbonate (PubChem CID: 10112); Sodium alginate (PubChem CID: 5102882); Ampicillin (PubChem CID: 6249); Oleic acid (PubChem CID: 445639); Linoleic acid (PubChem CID: 5280450); $\alpha$-Linolenic acid (PubChem CID: 5280934).

\section{Biomass production}

S. boulardii was inoculated in a Sabouraud Dextrose Broth (BIXON, Mexico) and incubated in a bath (Lab-line 3540 brand) at $25^{\circ} \mathrm{C}$, being constantly stirred at $150 \mathrm{rpm}$ over a period of $72 \mathrm{~h}$, counts were conducted every 12 hours $(0,12,24,36,48,60$, and 72$)$. The survival rate of $S$. boulardii was evaluated by means of the spread-plate counting method.

Enumeration of probiotic. The samples were diluted, i.e. $1 \mathrm{~g}$ of sample in $9 \mathrm{ml}$ sterile peptone water and then in a series of gradually less potent dilutions was obtained to $10^{10}$, an aliquot of $1 \mathrm{ml}$ of appropriate decimal dilutions were spread on agar potato dextrose (Merck) acidified with $10 \%$ sterilized tartaric acid to $\mathrm{pH} 3.5 \pm 0.1$ plate, and incubated for 5 days at $25^{\circ} \mathrm{C}$ [17]. S. boulardii colonies were quantified and expressed as the number of colony-forming units 
per gram $(\mathrm{CFU} / \mathrm{g})$. The greatest concentration at 24-hour time period was registered as $9.70 \pm$ $0.09 \mathrm{CFU} / \mathrm{ml}$. Thus, the conditions employed for obtaining biomass of $S$. boulardii were: incubation at $25^{\circ} \mathrm{C}$, combined with constant stirring at $150 \mathrm{rpm}$ for $24 \mathrm{~h}$.

\section{Microencapsulation}

The water-in-oil emulsion technique was used [18]. Microencapsulation was performed employing $1 \%$ sodium alginate, $0.05 \%$ inulin, and $0.05 \%$ mucilage extracted from cactus Opuntia ficus-indica, and subsequently adding the biomass obtained by centrifugation (resulting from the growth of the pure strain of $S$. boulardii in Sabouraud Dextrose Broth). Afterwards, $0.5 \% \mathrm{CaCO}_{3}$ was added to the aqueous mixture. Two hundred $\mathrm{mL}$ of canola oil was blended, separately with $2.5 \mathrm{~mL}$ of Tween 80 (oily phase). Constant stirring was maintained out from the aqueous to the oil phase, permitting the formation of the (water/oil) emulsion. Finally, $40 \mathrm{~mL}$ of the same oil was added but mixed with $1.7 \mathrm{ml}$ of glacial acetic acid to initiate the microencapsulation process. The result blend was stirred for 20 minutes to complete the formation of the capsules and then left to stand for $30 \mathrm{~min}$ before being decanted and filtered. The capsules were washed with $200 \mathrm{ml}$ of sterile distilled water and twice with $200 \mathrm{ml}$ of phosphate buffer solution $(\mathrm{pH}=7.2)$ to remove residual oil.

The survival of $S$. boulardii was evaluated before and after the microencapsulation process, for free cells was performed using by means of the spread-plate counting method as previously mentioned, while microencapsulated $S$. boulardii was disintegrated using the end of a sterile glass stirrer [18]. Subsequently, the quantification of $S$. boulardii was performed using the technique described above.

The microcapsules obtained were freeze-dried as follows: firstly, the microcapsules were frozen for $5 \mathrm{~h}$ at $-20^{\circ} \mathrm{C}$ and then placed in a freeze dryer with $4 \mathrm{~kg}$ capacity, applying pressure to $3 \mathrm{mmHg}$. - Samples were then dried at $20{ }^{\circ} \mathrm{C}$ for $24 \mathrm{~h}$. Parameters have been standardized in collaboration with the SioSi Alimentos S.A.P.I. de C.V, with reference to dehydration of food susceptible to heat and moisture from $75-85 \%$. The equipment was designed and built by SioSi Alimentos S.A.P.I. de C.V. (Morelia, Mich., Mexico). The morphology and size of the microcapsules were minutely observed with a scanning electron microscope. A sheet of carbon was placed on a brass plate, where the microcapsules were deposited. The samples were metallized with copper in a vacuum and put in a scanning electron microscope JEOL model JSM-mark SEG-7600F SEM, where the morphology and size were observed and measured.

\section{Yogurt-formulae}

To prepare the yogurt: inulin (4.0\%), vegetable oil (2.3\%), mono and di glycerides $(0.5 \%)$, gelatin $(0.125 \%)$, and sucrose $(5 \%)$ were added to skimmed milk $(88.07 \%)$. The mixture was stirred and pasteurized at $63{ }^{\circ} \mathrm{C}$ for $30 \mathrm{~min}$. Then, the mixture was left in an ice bath with salt for 10 min to reach approximately $4{ }^{\circ} \mathrm{C}$. Lactic cultures (L. bulgaricus and S. thermophilus) were then added at a concentration of $0.03 \mathrm{~g} / \mathrm{L}$ and incubated for 6 hours at $43{ }^{\circ} \mathrm{C}$. The end product was stirred and cooled to $4{ }^{\circ} \mathrm{C}$, and labelled formula $\mathrm{F} 1$. Two further products (using F1 as a base) were developed: F2, to which $S$. boulardii was added in the form biomass at a concentration of $0.5 \%$ cells; and F3, with added microencapsulated $S$. boulardii at a concentration of $0.5 \%$ biomass. 


\section{Freeze-dried products and survival tests of $S$. boulardii}

The F1, F2, and F3 products were freeze-dried using the technique as previously mentioned. The survival of $S$. boulardii was evaluated in fresh and freeze-dried products with the spread-plate counting method as previously mentioned. The quantification of microencapsulated $S$. boulardii was performed using the technique described above.

\section{Yogurt characteristics}

\section{Physicochemical analysis}

In order to measure the $\mathrm{pH}$, the yogurt powder was re-hydrated, using a ratio of 1 part dried powder to 3 parts of water, to reach a total volume of $100 \mathrm{~mL}$ employing a Hanna instruments pH 213 potentiometers. Acidity was calculated and expressed in terms of lactic acid. Color, with a Hunter Lab colorimeter (Model CX0795 Colorflex). Solubility determined as per the method proposed by Shittu and Lawal [19]. The wettability of the products assessed according to the modified static method, described by Kim et al. [20].

\section{Chemical composition}

Moisture, ash, protein, and lipids were measured using the methods AOAC [21]; dietary fiber content determined using the method of Prosky et al. [22]. Carbohydrate content obtained by difference, i.e. subtracting the sum of the protein, lipids, ash and fiber values from 100 . The fatty acid profile was measured by the Chem32 method using a gas chromatograph (Agilent Technologies 7890).

\section{Microbiological analysis}

A series of dilutions was prepared with sterile $0.1 \%$ buffered, peptone water. Appropriate dilutions were poured out and plated. An M17 agar (Oxoid Ltd., UK) was used to count $S$. thermophilus - and the plates were incubated aerobically at $37{ }^{\circ} \mathrm{C}$ for 48 h. L. bulgaricus was counted on MRS agar (Oxoid Ltd., UK) by incubating the plates anaerobically at $37{ }^{\circ} \mathrm{C}$ for $72 \mathrm{~h}$. Potato dextrose agar (Merck) acidified with $10 \%$ sterilized tartaric acid to $\mathrm{pH} 3.5 \pm 0.1$ was employed to determine the total yeast and mold. The plates were incubated at $25^{\circ} \mathrm{C}$ for a period of 5 days. The colonies were quantified and expressed as the number of colony-forming units per $\operatorname{gram}(\mathrm{CFU} / \mathrm{g})$.

\section{Survival of $S$. boulardii during storage}

For this study, $25 \mathrm{~g}$ of each freeze-drying yogurt were placed in separate foil pouches, supplied by SioSi Alimentos S.A.P.I. de C.V., and the survival of $S$. boulardii was evaluated as previously described, according to established sampling time periods, day 0, 12, 24, 36, 52, 68 and 84 . The freeze-dried yogurt samples were stored at $25{ }^{\circ} \mathrm{C}$ for 84 days, and the survival of $S$. boulardii monitored. The freeze-dried products were categorized as follows: F1 = Yogurt with inulin + vegetable oil (Control); F2 = Yogurt with inulin + vegetable oil $+S$. boulardii in free-cell form; F3 = Yogurt with inulin + vegetable oil $+S$. boulardii in microencapsulated form.

\section{Biological assay to ensure survival of $S$. boulardii in rat gastrointestinal tracts}

Twenty-four of 60-day-old Wistar rats, with an average weight of $240 \mathrm{~g}$, were acclimatized for four days before being randomly assigned to the experimental groups. Animal care and management were carried out under the guidelines of Mexican Official Standard NOM-062ZOO-1999. The animals were housed in individual cages in a room with a maintained temperature of $23 \pm 2{ }^{\circ} \mathrm{C}, 54 \pm 11 \%$ relative humidity and $12 \mathrm{~h}$ light/dark cycle. 
During this acclimatization period, each animal was fed a standard diet (an average of 60 calories/animal/day) and water purified. Having completed this stage, the rats were randomly divided into six treatments ( $\mathrm{n}=4$ rats) and fed ad libitum in addition to the experimental treatment and water for 14 days. Treatments were administered via an intragastrical cannula to ensure that animals ingested appropriate concentrations of saline solution $0.85 \%$, ampicillin solution $(5 \mathrm{mg} / \mathrm{mL}$ ) and $4 \mathrm{~g}$ rehydrated yogurt ( $3 \mathrm{~g}$ of distilled water per $1 \mathrm{~g}$ of freeze-dried yogurt). The treatments administered were the following: Treatment I: $1 \mathrm{ml}$ of saline solution was administered every $12 \mathrm{~h}$ for 7 days, followed by $4 \mathrm{ml}$ of of saline solution every $24 \mathrm{~h}$ for 7 days (control). Treatment II: $1 \mathrm{ml}$ of saline solution was administered every $12 \mathrm{~h}$ for 7 days, followed by $4 \mathrm{~g}$ of rehydrated formulate F2 every $24 \mathrm{~h}$ for 7 days. Treatment III: $1 \mathrm{ml}$ of saline solution was administered every $12 \mathrm{~h}$ for 7 days, followed by $4 \mathrm{~g}$ of rehydrated formulate F3 every $24 \mathrm{~h}$ for 7 days. Treatment IV: The rats were administered $2 \mathrm{mg}$ of ampicillin / $100 \mathrm{~g}$ body weight every $12 \mathrm{~h}$ for 7 days, followed by $4 \mathrm{ml}$ of saline solution every $24 \mathrm{~h}$ for 7 days (control). Treatment V: The rats were administered $2 \mathrm{mg}$ ampicillin / $100 \mathrm{~g}$ body weight every $12 \mathrm{~h}$ for 7 days, followed by $4 \mathrm{~g}$ of rehydrated formulate F2 every $24 \mathrm{~h}$ for 7 days. Treatment VI: The rats were given $2 \mathrm{mg}$ ampicillin / $100 \mathrm{~g}$ body every $12 \mathrm{~h}$ for 7 days, followed by $4 \mathrm{~g}$ of rehydrated formulate $\mathrm{F} 3$ every $24 \mathrm{~h}$ for 7 days.

The F2 formulation contained $7.17 \pm 0.17 \log \mathrm{CFU} / \mathrm{g}$ of $S$. boulardii as free cells and F3 contained $6.86 \pm 0.24 \log \mathrm{CFU} / \mathrm{g}$ of $S$. boulardii in microencapsulated form.

Feces from each treatment were collected aseptically, prior to administration of the probiotic (day 1) and following its administration (days 3, 5, 7). Microbiological analysis of the feces was performed according to the methodology as previously mentioned to evaluate the presence of S. boulardii in the feces during yogurt administration. Colonies were reported as $\mathrm{CFU} / \mathrm{g}$.

The animals were sacrificed after the administration of treatments and a portion of the colon was resected. The specimen was weighed, washed with sterile saline solution, and placed in Petri dishes. An incision was made to the intestinal lining with a scalpel. A bacteriological loop was used to scrape the intestine to obtain a representative sample. The intestinal content was resuspended in saline solution and subsequently plated, using the above-mentioned technique. Isolated colonies were identified by testing assimilation of sugars - employing the API $20 \mathrm{C}$ system AUX ${ }^{\circledR}$.

\section{Data analysis}

The data obtained were statistically analyzed as per using the Tukey-Kramer test $(\mathrm{P}<0.05)$. Statistical analysis was performed using the program JMP6 statistical software (SAS Institute, Cary, NC, USA)

\section{RESULTS AND DISCUSSION}

\section{Microencapsulation}

The number of viable cells of $S$. boulardii after microencapsulation process was reduced by 1.59 logarithmic units, from $9.70 \pm 0.09$ to $8.11 \pm 0.10 \mathrm{CFU} / \mathrm{g}$. Microcapsules containing S. boulardii are shown in Figure 1. The micro-encapsulated S. boulardii was seen to be agglomerated or of a spherical form. When 30 microcapsules were measured individually they had an average diameter of 7.5 microns, i.e. similar to that reported average size $9.2 \propto$ for Zamora-Vega et al. [18]. 


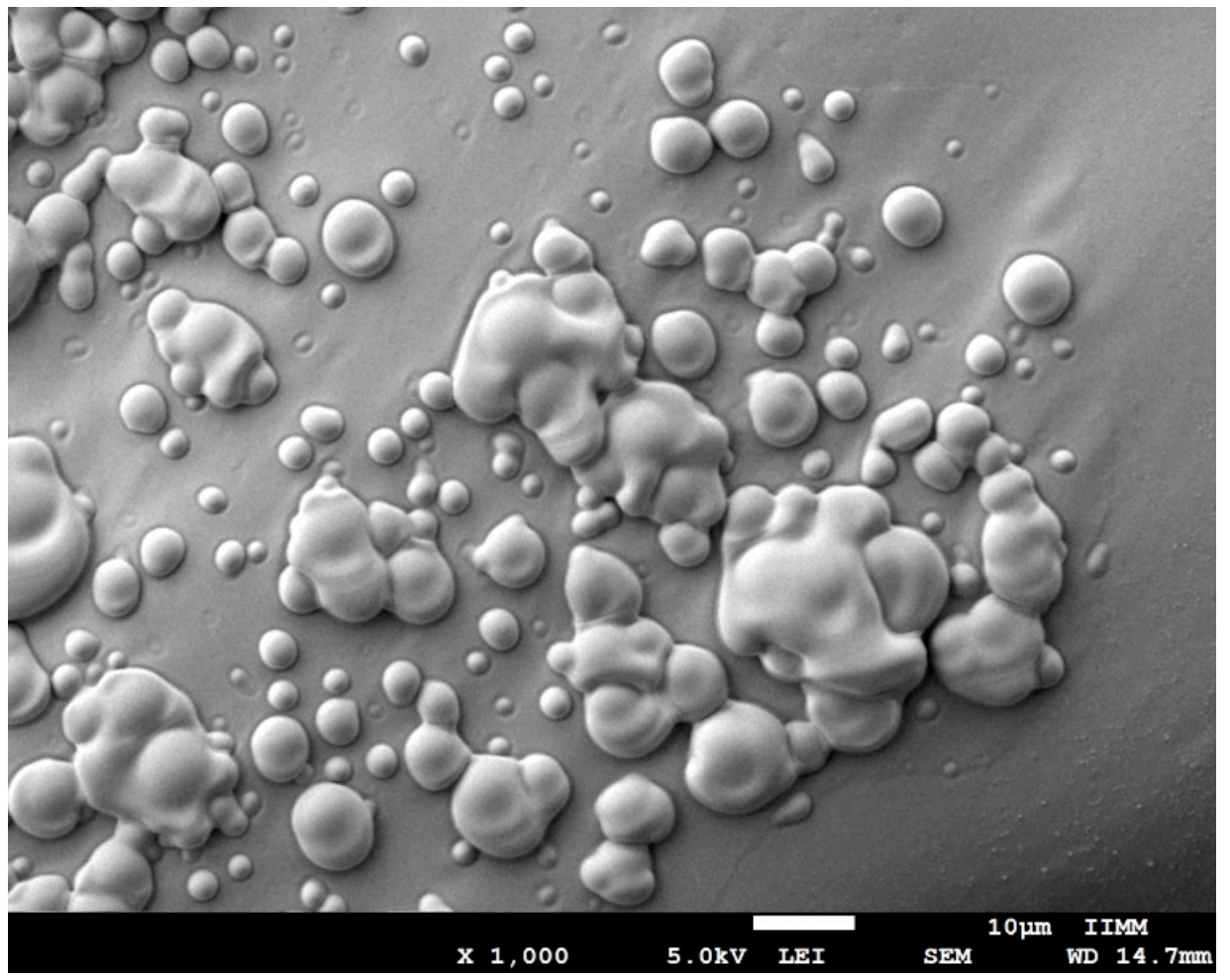

Figure 1. Microcapsules containing S. boulardii.

\section{Freeze-dried yogurt}

The survival of $S$. boulardii before and after freeze-drying is shown in Table 1. The variance analysis showed no significant difference $(\mathrm{p}<0.05)$ for F2 and F3. Therefore, the conditions used for carrying out the freeze-drying process did not affect the survival of $S$. boulardii during storage.

The concentration of yeasts in this specific type of fermented food, should be present in amounts greater than $1 \times 10^{4} \mathrm{CFU} / \mathrm{g}$ (CODEX STAN 243-2003). Consequently, the processed food evaluated in our research does meet the criteria established for this type of product and can therefore be considered a source of probiotics due to the formulations contained, 8.94-Log $\mathrm{CFU} / \mathrm{g}$ for $\mathrm{F} 2$ and 7.41-Log CFU/g for F3.

Table 1. Survival of probiotics present in the fresh \& freeze-dried yogurt

\begin{tabular}{ccc}
\hline Formulae & $\begin{array}{c}\text { Fresh yogurt } \\
\text { Log CFU/g }\end{array}$ & $\begin{array}{c}\text { Freeze-dried yogurt } \\
\text { Log CFU/g }\end{array}$ \\
\hline F1 & ND & ND \\
F2 & $9.05 \pm 0.39^{\mathrm{a}}$ & $8.94 \pm 0.66^{\mathrm{a}}$ \\
F3 & $7.73 \pm 0.23^{\mathrm{a}}$ & $7.41 \pm 0.12^{\mathrm{a}}$ \\
\hline
\end{tabular}

Results are expressed as mean \pm standard deviations (SD) of three determinations. $\mathrm{ND}=(<1-\mathrm{Log} \mathrm{CFU} / \mathrm{g})$.

${ }^{a}$ The same letter in the same line is not significantly different $(\mathrm{p}<0.05)$. F1 = Yogurt + inulin + vegetable oil (Control). F2 = Yogurt + inulin + vegetable oil $+0.5 \%$ of $S$. boulardii. F3 = Yogurt + inulin + vegetable oil $+0.5 \%$ of $S$. boulardii microencapsulated. 


\section{Yogurt-characterization}

\section{Physicochemical analysis}

Table 2 illustrates that the color parameter luminosity "L" where 0 represents black and 100 white - was not statistically different $(\mathrm{p}<0.05)$ with reference to $\mathrm{F} 1, \mathrm{~F} 2$, and F3 products (ranging from 84 to 86 ). The "b" parameter, associated with color yellow for positive values, showed no significant difference $(\mathrm{p}<0.05)$ between them either. Consequently, the incorporation of $S$. boulardii-whether as free or microencapsulated cells-did not affect these parameters: the end products had the white color, characteristic of yogurt, but with a slightly yellow hue attributed to the addition of palm oil. The $\mathrm{pH}$ ranged from 4.4 to 4.5 and was thereby not notably at variance $(\mathrm{p}<0.05)$ when comparing the three samples (Table 2$)$. The acid $\mathrm{pH}$ of yogurt helps to preserve and also prevent the growth of undesirable microorganisms - including pathogens.

We observed important variants $(p<0.05)$ in the lactic acid values (Table 2$)$ in the samples containing $S$. boulardii. The F2 product, of greater lactic acid and containing "free" S. boulardii had slightly higher lactic acid than product F1 (control sample) — probably due to the production of organic acids - such as the acetic acid-during the fermentation of free sugars by the yeast. Product F3 was less lactic acid, which may have occurred because the yeasts were microencapsulated and had no direct contact with the yogurt. It is essential that yogurt have a minimum lactic acid of 0.5 [23]. However, one must also note that all the products developed in this report meet this parameter.

Wettability and solubility tests were performed to evaluate the instantaneous hydration properties of the freeze-dried products (Table 2). Determinations were exacted taking two particle sizes into consideration. None of the three products demonstrated any significant difference $(\mathrm{p}<0.05)$ with reference to its solubility-which ranged from $78.53 \%$ to $79.53 \%$ in F3 for a particle $1-2 \mathrm{~mm}$ in diameter. When the particle size was $0.5-1 \mathrm{~mm}$, the solubility decreased significantly in F2 and F3 compared to the control (F1). Product F3 showed the lowest solubility (70.62\% when compared to $76.40 \%$ in F2). Wettability tests show that in F1 and F2, particle size did have an impact on wetting time, which increased by approximately 20 min for smaller particles compared to the larger ones. Showing to the fact that the larger particles were immersed faster than the smaller. However, noteworthy differences $(p<0.05)$ were observed in particles measuring $0.5-1 \mathrm{~mm}$, which decreased the wettability time of F3 with reference to F1 and F2. Product F3 showed similar wettability for 1 to $2 \mathrm{~mm}$ (5 min) or 0.5 to $1.0 \mathrm{~mm}$ (5.29 $\mathrm{min})$ particles. The microcapsules of this product favored rapid wetting, possibly because they were prepared with hydrocolloids and demonstrated greater affinity for water, and that tendency regardless of particle size. Overall, 1-2 $\mathrm{mm}$ particles had better wettability characteristics than those of $0.5-1 \mathrm{~mm}$ in all three formulae. 
Table 2. Physicochemical analysis of yogurts.

\begin{tabular}{|c|c|c|c|c|}
\hline Product & Parameter & F1 & F2 & F3 \\
\hline Rehydrated & $\mathrm{pH}$ & $4.49 \pm 0.01^{\mathrm{a}}$ & $4.43 \pm 0.01^{\mathrm{a}}$ & $4.50 \pm 0.06^{\mathrm{a}}$ \\
\hline Rehydrated & Lactic acid $(\%)$ & $0.81 \pm 0.009^{\mathrm{b}}$ & $0.85 \pm 0.009^{\mathrm{a}}$ & $0.71 \pm 0.005^{\mathrm{c}}$ \\
\hline Freeze-dried & Color L & $85.61 \pm 0.49^{\mathrm{a}}$ & $85.24 \pm 0.57^{\mathrm{a}}$ & $84.42 \pm 0.14^{\mathrm{a}}$ \\
\hline Freeze-dried & Color b & $15.81 \pm 0.30^{\mathrm{a}}$ & $15.75 \pm 0.12^{\mathrm{a}}$ & $15.85 \pm 0.14^{\mathrm{a}}$ \\
\hline \multirow[t]{2}{*}{ Freeze-dried } & Solubility (\%) & & & \\
\hline & $\begin{array}{l}\text { Particle size } 1-2 \\
\mathrm{~mm}\end{array}$ & $79.53 \pm 0.68^{\mathrm{a}}$ & $79.00 \pm 0.78^{\mathrm{a}}$ & $78.35 \pm 0.86^{\mathrm{a}}$ \\
\hline \multirow[t]{2}{*}{ Freeze-dried } & Solubility (\%) & & & \\
\hline & $\begin{array}{l}\text { Particle size } 0.5-1 \\
\mathrm{~mm}\end{array}$ & $78.55 \pm 0.86^{\mathrm{a}}$ & $76.40 \pm 1.09^{\mathrm{a}}$ & $70.62 \pm 0.64^{b}$ \\
\hline \multirow[t]{2}{*}{ Freeze-dried } & Wettability (mins) & & & \\
\hline & $\begin{array}{l}\text { Particle size } 1-2 \\
\mathrm{~mm}\end{array}$ & $13.23 \pm 0.94^{\mathrm{a}}$ & $13.16 \pm 0.55^{\mathrm{a}}$ & $5.00 \pm 0.45^{\mathrm{b}}$ \\
\hline \multirow[t]{2}{*}{ Freeze-dried } & Wettability (mins) & & & \\
\hline & $\begin{array}{l}\text { Particle size } 0.5-1 \\
\mathrm{~mm}\end{array}$ & $33.9 \pm 0.30^{\mathrm{a}}$ & $32.33 \pm 1.02^{b}$ & $5.29 \pm 0.08^{\mathrm{c}}$ \\
\hline
\end{tabular}

Results are expressed as mean \pm standard deviations (SD) of three determinations. ${ }^{\text {a,b }}$ The different letter in the same line is significantly different $(\mathrm{p}<0.05)$. F1 = Yogurt with inulin + vegetable palm-oil added (Control). F2 $=$ Yogurt with inulin + vegetable palm-oil $+0.5 \%$ of $S$. boulardii added. F3 = Yogurt with inulin + vegetable palm-oil $+0.5 \%$ of $S$. boulardii microencapsulated added. Rehydrated product (3 parts of water: 1 part of freeze-dried product).

\section{Chemical composition analysis}

The chemical compositions of F1, F2, and F3 products are shown in Table 3. All three formulae demonstrated similar moisture content from 5.30\% (F2) to 5.63\% (F3). Protein content in F1 was not significantly modified $(\mathrm{P}<0.05)$ by the addition of $S$. boulardii. Nevertheless, an increase was noted in the number of lipids in F3 (15.43\%) compared to F1 (11.01\%) and F2 $(11.53 \%)$. The rise was due to the microcapsules formula plus the water-in-oil-emulsion process resulting in higher lipid reading in the $\mathrm{F} 3$ product.

Milk fat contains approximately $70 \%$ saturated fatty acids, which can raise low-density lipoprotein (LDL), increasing the risk of cardiovascular ailments. Therefore, milk fat consumption should ideally be limited [24]. One objective of this study was to replace milk fat with vegetable palm oil to augment the content of unsaturated fatty acids - in particular essential polyunsaturated fatty acids (PUFAs) - such as omega-3 (fatty acid $\alpha$-linolenic) or omega-6 (fatty acid linoleic), which cannot be produced by the human body. For this reason, some PUFAs, e.g. acid $\alpha$-linolenic or acid linoleic and derivatives [eicosapentaenoic acid (EPA) or docosahexaenoic acid (DHA)], have to be consumed directly from food [25]. The amount of fat recommended for daily consumption is approximately $30 \%$ of total energy intake, of which $10 \%$ should be from saturated fatty acids, 6 to $11 \%$ from polyunsaturated fatty acids ( 2.5 to $9 \%$ of 
linoleic acid and $0.5 \%$ to $2.0 \%$ of $\alpha$-linolenic acid) in addition to monounsaturated fatty acid obtained by subtraction [26]. For example, with a typical diet of $2000 \mathrm{kcal}$ per day, using $30 \%$ of energy from total fat and the minimum intake percentages to prevent deficiency symptoms of $2.5 \%$ linoleic acid and $0.5 \% \alpha$-linolenic acid, gives us $66 \mathrm{~g} / \mathrm{day}, 5.5 \mathrm{~g} / \mathrm{day}$ and $1.1 \mathrm{~g} / \mathrm{day}$ respectively [27].

The formulae prepared in this study contained a low quantity of saturated fatty acids: 3.32 $\mathrm{g} / 11.01 \mathrm{~g}$ fat (F1), $3.74 \mathrm{~g} / 11.53 \mathrm{~g}$ fat (F2), and $3.05 \mathrm{~g} / 15.43 \mathrm{~g}$ fat (F3). Consequently, the three products had a higher proportion of unsaturated fatty acids: $7.69 \mathrm{~g} / 11.01 \mathrm{~g}$ fat (F1), $7.79 \mathrm{~g} / 11.53$ $\mathrm{g}$ fat (F2) and $12.38 \mathrm{~g} / 15.43 \mathrm{~g}$ fat (F3) (Table 3). The most abundant mono-unsaturated fatty acid found in this study, was the oleic - at $4.78 \mathrm{~g} / 11.01 \mathrm{~g}$ fat, $4.91 \mathrm{~g} / 11.53 \mathrm{~g}$ fat and $8.29 \mathrm{~g} / 15.43 \mathrm{~g}$ fat for F1, F2, and F3 respectively. This is significant due to the fact that reported increased intake of oleic acid raises the HDL-cholesterol fraction and thereby reduces cardiovascular risk [28]. The products demonstrated had linoleic acid values of $2.07 \mathrm{~g} / 11.01 \mathrm{~g}$ fat, $2.08 \mathrm{~g} / 11.53 \mathrm{~g}$ fat, and $2.70 \mathrm{~g} / 15.43 \mathrm{~g}$ fat for F1, F2, and F3 respectively. These results are certainly worthy of note, as intake of linoleic acid is known to exert a stabilizing action on the cell membrane, producing an anti-arrhythmic effect, inhibits platelet aggregation in addition to other favorable effects on lipid profile (decreased triglycerides and VLDL cholesterol and HDL cholesterol may possibly increase) and hypotensive properties [28]. The products in our study contain $0.36 \mathrm{~g} \alpha$-linolenic $\mathrm{acid} / 11.01 \mathrm{~g}$ fat, $0.37 \mathrm{~g} \alpha$-linolenic acid/11.53 $\mathrm{g}$ fat, and $0.79 \mathrm{~g} \alpha$-linolenic acid/15.43 $\mathrm{g}$ fat for F1, F2, and F3, respectively. Omega-3 may act as therapeutic agent with a significant role in the treatment of inflammatory illnesses — including cardiovascular and neurodegenerative ailments [29].

Table 3. Chemical composition analysis of freeze-dried products.

\begin{tabular}{lccc}
\hline $\begin{array}{c}\text { Chemical } \\
\text { compounds } \\
(\%)\end{array}$ & F1 & F2 & F3 \\
\hline Moisture & & & $5.63^{\mathrm{a}}$ \\
Protein & $5.40^{\mathrm{a}}$ & $5.3^{\mathrm{a}}$ & $13.59^{\mathrm{a}}$ \\
Ashes & $13.08^{\mathrm{a}}$ & $13.53^{\mathrm{a}}$ & $3.02^{\mathrm{b}}$ \\
Carbohydrates & $3.16^{\mathrm{a}}$ & $3.27^{\mathrm{a}}$ & $62.33^{\mathrm{b}}$ \\
Fat & $67.35^{\mathrm{a}}$ & $66.37^{\mathrm{a}}$ & $15.43^{\mathrm{a}}$ \\
Saturated (g) & $11.01^{\mathrm{b}}$ & $11.53^{\mathrm{b}}$ & 3.05 \\
Monounsaturated (g) & 3.32 & 3.74 & 8.33 \\
Polyunsaturated (g) & 4.80 & 4.92 & 3.89 \\
$\quad$ Oleic acid (g) & 2.68 & 2.66 & 8.29 \\
$\quad$ Linoleic acid (g) & 4.78 & 4.91 & 2.70 \\
$\quad$-Linolenic acid (g) & 2.07 & 2.08 & 0.79 \\
& 0.36 & 0.37 & \\
\hline
\end{tabular}

Results are expressed as mean \pm standard deviations (SD) of three determinations. ${ }^{\text {a, } b}$ The different letter in the same line is significantly different $(\mathrm{p}<0.05)$. F1 = Yogurt with inulin + vegetable palm-oil added (Control). F2 = Yogurt with inulin + vegetable palm-oil $+0.5 \%$ of $S$. boulardii added. F3 = Yogurt with inulin + vegetable palm-oil $+0.5 \%$ of $S$. boulardii microencapsulated added. 


\section{Microbiological analysis}

Neither total coliforms nor molds were detected (Table 4). Moreover, these formulae showed a concentration of lactic acid bacteria of approximately 8-log CFU/g - higher than standards used as a reference for a minimum amount of $7-\log \mathrm{CFU} / \mathrm{g}$ to warrant the official quantification of a "probiotic" [30]. Thus, the products obtained in this work may be denoted as probiotics. The viability of the bacteria was not affected by the adding of $S$. boulardii in F2 or F3.

Table 4. Microbiological analysis of freeze-dried yogurts.

\begin{tabular}{lllll}
\hline Log-CFU/g & F1 & F2 & F3 & CODEX STAN 243-2003 \\
\hline Total coliforms & ND & ND & ND & Maximum 1 \\
Molds & ND & ND & ND & Maximum 1 \\
Lactic bacteria & $8.31 \pm 0.2^{\mathrm{a}}$ & $8.47 \pm 0.29^{\mathrm{a}}$ & $8.06 \pm 004^{\mathrm{a}}$ & Minimum 7 \\
\end{tabular}

Results are expressed as mean \pm standard deviations (SD) of three determinations. ${ }^{a}$ The different letter in the same line is significantly different $(\mathrm{p}<0.05)$. $\mathrm{ND}=$ Not detected $(<1 \mathrm{CFU} / \mathrm{g})$. F $1=$ Yogurt with inulin + vegetable palm-oil added (Control). F2=Yogurt with inulin + vegetable palm-oil + $0.5 \%$ of $S$. boulardii added. F3=Yogurt with inulin + vegetable palm-oil $+0.5 \%$ of $S$. boulardii microencapsulated added.

\section{Survival of $S$. boulardii during storage at $25^{\circ} \mathrm{C}$}

Figure 2 shows that the viability of $S$. boulardii decreased with time. The minimum concentration of $S$. boulardii (yeast) that this kind of fermented product must have in order to be considered a probiotic dairy item is 4-log CFU / $\mathrm{g}$ [30]. In the case of F2, showed a concentration of 7.12-Log CFU/g on day 0 and 4.66 -Log CFU/g on day 68 and 3.93 -Log $\mathrm{CFU} / \mathrm{g}$ on day 84. F3 had a concentration of $6.55-\mathrm{Log} \mathrm{CFU} / \mathrm{g}$ on day 0 and 4.40-Log CFU/g on day 84 maintaining a yeast concentration sufficiently acceptable as a probiotic. During the whole period, the concentration of yeast present in sample F3 was sufficient to be of probiotic food level to difference of F2.

The loss of $S$. boulardii viability in F2 was of $3.92 \log$ units, in F3, the decrease was only $2.15 \log$ units - illustrating the protective effect of the microcapsules. A study demonstrated that when $S$. boulardii was incorporated into fresh cheese, viability was increased $1.22-\log$ $\mathrm{CFU} / \mathrm{g}$ when the probiotic was microencapsulated-compared to free cells, over 35 days of storage at 4

${ }^{\circ} \mathrm{C}$ [18]. The protective effect of the microcapsules should be specially noted, given that $S$. boulardii viability is markedly affected during the storage phase, that oxygen content, high temperatures, low $\mathrm{pH}$, water activity, and elevated concentrations of solutes can affect the viability of probiotics [31, 32]. Freeze-drying did not affect the survival rate of $S$. boulardii - either as free cells or in microencapsulated form. But over time, viability significantly decreased during storage at $25^{\circ} \mathrm{C}$. 


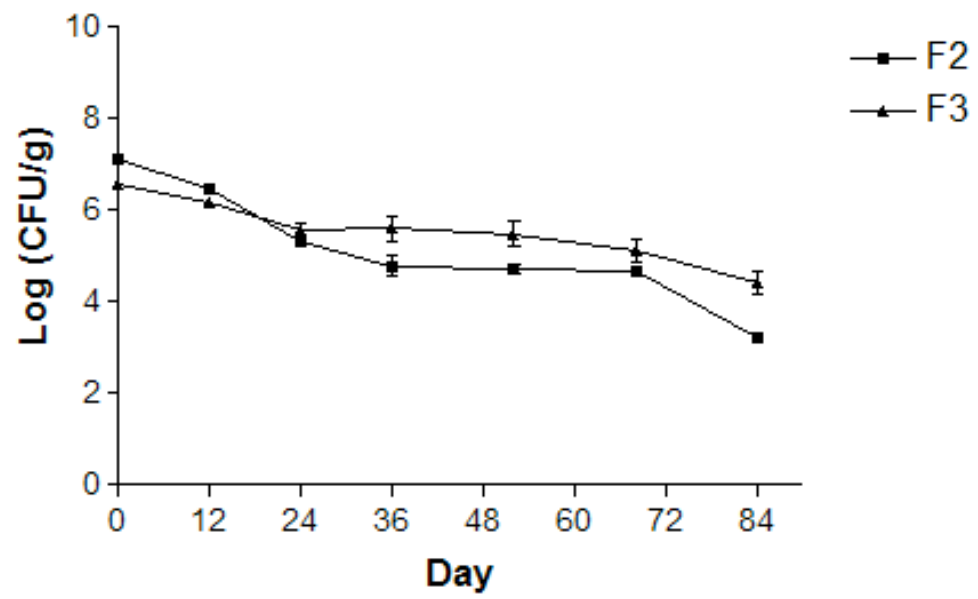

Figure 2. Values represent mean \pm standard deviation of tree determinations. S. boulardii survival according to time lapse at $25^{\circ} \mathrm{C}$ : F2 $=$ Yogurt with inulin + vegetable oil $+0.5 \%$ of S. boulardii. F3 = Yogurt with inulin + vegetable oil $+0.5 \%$ of $S$. boulardii microencapsulated.

\section{Biological assay and survival of $S$. boulardii in rat gastrointestinal tract}

Table 5 shows the survival of $S$. boulardii in fecal samples of the six treatments. $S$. boulardii was not detected in treatments I, II, III, and IV, over a period of seven days. Treatments I and IV, which were the control, were not given S. boulardii. However, for treatment II and III, fed yogurt containing $S$. boulardii (either as free cells or in microencapsulated form, respectively) - no survival $S$. boulardii was found in the feces.

Furthermore, $S$. boulardii was also not discovered in survival form in the colon, probably because the intestinal flora in these test animals was typically balanced (i.e. normal flora), and was not affected by the administration of an ampicillin, or pathology in the treatments I, II, III, and IV (Table 5). Some authors have reported that $S$. boulardii can only be hosted in the digestive tract of axenic (totally bacteria-free) animals. Nevertheless, a study demonstrated that in holoxenic animals (complex flora), S. boulardii was rapidly eliminated [33]. Thus, when flora was "normal", $S$. boulardii was not deposited in the gastro-intestinal tract and, therefore, not viable in the colon - as appreciated in our investigation. Conversely, S. boulardii was found in the feces of treatments V and VI, which correspond to animals administered ampicillin for seven days prior to the probiotic. This antibiotic (ampicillin) damages intestinal flora - due to its $40 \%$ absorption level—and the remaining unabsorbed drug passes such as through the gastro- intestinal tract destroying all susceptible microorganisms. In this path and leaving behind free "binding sites" where $S$. boulardii can initially settle in the colon, followed by excretion after five or seven days (Table 5).

The excretion of probiotics may occur because $S$. boulardii in the early stage of administration, occupy fill the "binding sites" of the gastro-intestinal tract and consequently begin to appear in the feces [34], base these criteria on the fact that, for the proved deposit of a probiotic in the gastro-intestinal tract, its suffices that the colonizing microorganism be present in the stool culture-signifying its viability as it courses through the entire gastrointestinal tract. 
Table 5. Survival of S. boulardii in feces of Wistar rats.

\begin{tabular}{|c|c|c|c|c|c|}
\hline \multirow[t]{3}{*}{ Treatment } & \multicolumn{4}{|c|}{$\mathrm{Log} \mathrm{CFU} / \mathrm{g}$ in feces } & \multirow[t]{2}{*}{$\begin{array}{l}\text { Log CFU/g } \\
\text { in colon }\end{array}$} \\
\hline & & & Day & & \\
\hline & 1 & 3 & 5 & 7 & 7 \\
\hline I & ND & ND & ND & ND & ND \\
\hline II & ND & ND & ND & ND & ND \\
\hline III & ND & ND & ND & ND & ND \\
\hline IV & ND & ND & ND & ND & ND \\
\hline $\mathrm{V}$ & ND & ND & $6.02 \pm 0.37^{\mathrm{a}}$ & $5.10 \pm 0.57^{\mathrm{a}}$ & $2.32 \pm 0.48^{\mathrm{a}}$ \\
\hline VI & ND & ND & $4.98 \pm 0.36^{\mathrm{b}}$ & $4.55 \pm 0.41^{\mathrm{a}}$ & $3.10 \pm 0.72^{\mathrm{a}}$ \\
\hline
\end{tabular}

Results are expressed as mean \pm standard deviations (SD) of four determinations. ${ }^{a, b}$ The different letter in the same line is significantly different $(\mathrm{p}<0.05)$ for $\mathrm{Log} \mathrm{CFU} / \mathrm{g}$ in faeces. ${ }^{\mathrm{a}}$ The different letter in the same column is significantly different $(\mathrm{p}<0.05)$ for $\mathrm{Log} \mathrm{CFU} / \mathrm{g}$ in colon. $\mathrm{ND}=$ No detected $(<1-\log$ $\mathrm{CFU} / \mathrm{g})$.

According to our study, in the two treatments, the colonization of the gastro-intestinal tract of the animals was corroborated - in that colonies were viable in feces and colon. The adhesion mechanism during colonization was probably realized by means of mannoproteins, known as adhesins, present on the $S$. boulardii cell membrane, which can bind to specific amino-acid or sugar residues on the surface of other cells. These receptors can be for D-galactose, Nacetylgucosamine, $\mathrm{N}$-acetylgalactosamine, or $\mathrm{N}$-acetylneuraminic acid; associated with intestinal glycoproteins, and in carbohydrates as mucin receptors that can function as both pathogenic and probiotic bacteria [35].

Microencapsulation of the $S$. boulardii proved tendency more efficient than its administration by the $S$. boulardii as free cells. The survival of $S$. boulardii as free cells and as microencapsulated form was of 2.33 and $3.10 \mathrm{log}$ CFU/g respectively.

Saccharomyces boulardii strains can assimilate a variety of sugars including: D-glucose, Glycerol, D-galactose, D-maltose, D-Cellobiose, D-sucrose, D-trehalose, and D-raffinose dependent on the strain [36]. The quoted authors analyzed nine strains of S. boulardii and reported differences in sugar assimilation. However, it was discovered that four sugars were assimilated by all nine strains: i.e. D-glucose, D-maltose, D-sucrose, and D-raffinose - and said sugars were assimilated by the strain of $S$. boulardii that was used and isolated in this study. See Table 6.

The API AUX 20® system, specializing in assimilation of sugars, was the one used to identify $S$. boulardii in this study. Strains isolated from colon and feces in groups V and VI, showed the same chemical profile demonstrated by the $S$. boulardii strain present in the yogurt analyzed here. Nine strains of $S$. boulardii studied displayed a similar outline of assimilation of sugars [36] as $S$. boulardii strain used in this study. The biochemical profile of $S$. boulardii strains isolated from colon and feces are presented in Table 6. 
Table 6. Identification of probiotic for test assimilation of sugars using the API 20C systemAUX®.

\begin{tabular}{cc}
\hline Sugar & S. boulardii \\
\hline D-glucose & + \\
Glycerol & - \\
Calcium 2-keto-gluconate & - \\
L- arabinose & - \\
D-Xylose & - \\
Adonitol & - \\
Xilitol & + \\
D-Galactose & - \\
Inositol & - \\
D-sorbitol & + \\
Methyl- $\alpha$-D Glucopyranoside & - \\
N-Acetyl- Glucosamine & - \\
D-Celobiose & - \\
D-Lactose & + \\
D-Maltose & + \\
D-Sucrose & - \\
D-Trehalose & - \\
D-Melezitose & + \\
D-Raffinose & \\
\hline & \\
\hline
\end{tabular}

\section{CONCLUSIONS}

The Saccharomyces boulardii was added in microencapsulated form and as free cells to yogurt, was freeze-dried, being the freeze-drying process an ideal method of preservation. Microencapsulation increased the viability of $S$. boulardii compared to yeast added as free cells, therefore extending the full benefits of the product. The prepared formulae containing $S$. boulardii can be considered probiotic food; in controlled groups of experimental rats with intestinal flora affected by ampicillin, ingested yeast-either as free cells or in microencapsulated form was found in feces, thereby demonstrating its resistance to gastric $\mathrm{pH}$, bile salts and certain "digestive" enzymes and, finally, its ability to survive in the colon.

Competing interests: The authors have no conflict of interest.

Author's contributions: Tranquilino-Rodriguez performed the experimental research, Martinez- Flores and Rodiles-Lopez designed the study, Zamora-Vega designed the probiotic encapsulation stage, Salgado-Garciglia and Perez-Sanchez contributed to the analysis of results.

\section{Acknowledgements}

This work was supported by the Coordinacion de la Investigacion Cientifica. Universidad Michoacana de San Nicolas de Hidalgo (CIC-UMSNH), project 26.1, 2014-2015. Eunice Tranquilino Rodriguez gratefully acknowledges the support of CONACyT, in the form a scholarship received for MSc studies. Thanks to SioSi Alimentos, freeze-dry industry, Mexico. 


\section{REFERENCES}

1. Jebb S: Dietary determinants of obesity. Obes Rev, 2007, 8(s1):93-97.

2. Choi J, Zhao J: Consumers' behaviors when eating out: Does eating out change consumers' intention to eat healthily?. Brit Food J, 2014, 116:494-509.

3. Goetzke B, Spiller A: Health-improving lifestyles of organic and functional food consumers. Brit Food J, 2014, 116:510-526.

4. Gramza-Michałowska A, Kobus-Cisowska J, DKmiecik D, Korczak J, Helak B, Dziedzic K, Górecka D: Antioxidative potential, nutritional value and sensory profiles of confectionery fortified with green and yellow tea leaves (Camellia sinensis). Food Chem, 2016, 211:448-454.

5. Hasler C, Brown A: American Dietetic Association. Position of the American Dietetic Association: functional foods. J Amer Diet Assoc, 2009, 109:735-746.

6. Ramirez-Chavarin ML, Wacher C, Eslava-Campos CA, Perez-Chabela ML. Probiotic potential of thermotolerant lactic acid bacteria strains isolated from cooked meat products. Int Food Res J, 2013, 20(2):991-1000.

7. Pandey KR, Naik SR, Vakil BV: Probiotics, prebiotics and synbiotics-a review. J Food Sci Techn, 2015, 52:7577-7587.

8. FAO/WHO report. 2002. Food and Agricultural Organization/World Health Organization Working Group. Guidelines for the evaluation of probiotics in food. London, Ontario, Canada, April 30 and May 1.

9. Ranadheera C, Evans C, Adams M, Baines S: In vitro analysis of gastrointestinal tolerance and intestinal cell adhesion of probiotics in goat's milk ice cream and yogurt. Food Res Int, 2012, 49:619-625

10. Kechagia M, Basoulis D, Konstantopoulou S, Dimitriadi D, Gyftopoulou K, Skarmoutsou N, Fakiri EM: Health benefits of probiotics: a review. ISRN Nutrition, 2013, 1-7.

11. Martins F, Rodrigues A, Tiago F, Penna F, Rosa C, Arantes R, Nardi R, Neves M, Nicoli $\mathrm{J}$ : Saccharomyces cerevisiae strain 905 reduces the translocation of Salmonella enterica serotype Typhimurium and stimulates the immune system in gnotobiotic and conventional mice. J Med Microbiol, 2007, 56:352-359.

12. Tripathi M, Giri S: Probiotic functional foods: Survival of probiotics during processing and storage. J Funct Foods, 2014, 9:225-241.

13. Vandenplas Y: Saccharomyces boulardii in childhood. Eur J Pediatr, 2009, 168: 253-65.

14. Hudson E, Fasken M, McDermott C, McBride S, Kuiper E, Guiliano D, Lamb T: Functional heterologous protein expression by genetically engineered probiotic yeast Saccharomyces boulardii. PloS ONE, 2014, 9:112-660.

15. Bakr I, Mohamed T, Tammam A, El-Gazzar F: Characteristics of bioyogurt fortified With Fennel honey. Int J Curr Microbiol App Sci, 2015, 4:959-970.

16. Al-Kadamany E, Khattar M, Haddad T, Toufeili I: Estimation of shelf-life of concentrated yogurt by monitoring selected microbiological and physicochemical changes during storage. LWT-Food Sci Technol, 2003, 36:407-414.

17. Cardoso VM, Borelli BM, Lara CA, Soares MA, Pataro C, Bodevan EC, Rosa CA: The influence of seasons and ripening time on yeast communities of a traditional Brazilian 
cheese. Food Res Int, 2015, 69:331-340.

18. Zamora-Vega R, Montañez-Soto JL, Martínez-Flores HE, Flores-Magallón R, MuñozRuiz CV, Venegas-González, J, Ariza OTDJ: Effect of incorporating prebiotics in coating materials for the microencapsulation of Sacharomyces boulardii. Int J Food Sci Nutr, 2012, 63(8):930-935.

19. Shittu T, Lawal M: Factors affecting instant properties of powdered cocoa beverages. Food Chem, 2007, 100:91-98.

20. Kim E, Chen X, Pearce D: Surface characterization of four industrial spray -dried dairy powders in relation to chemical composition, structure and wetting property. Colloids Surf B Biointerfaces, 2002, 26:197-212.

21. AOAC. Official Methods of Analysis. 15th Edition. Association of Official Analytical Chemists, Washington DC. EUA, 1990.

22. Prosky L, Scheweizer T, Furda I, Devries J: Determination of insoluble, soluble, and total dietary fiber in food and products: Interlaboratory study. J Assoc Off Anal Chem, 1988, 71:1018-23.

23. NOM-181-SCFI-2010

http://dof.gob.mx/nota_detalle.php?codigo $=5167303 \&$ fecha $=16 / 11 / 2010$ Accesed in 07/08/2016

24. AHA. American Heart Association Scientific Statement. 2006. Diet and lifestyle recommendations revision: a scientific statement from the American Heart Association Nutrition Committee. Circulation, 114, 82-96

25. Lupton JR, Blumberg JB, L'Abbe M, LeDoux M, Rice HB, von Schacky C, Yaktine A, Griffiths JC: Nutrient reference value: non-communicable disease endpoints-a conference report. Eur J Nutr, 2016, 55:1-10.

26. FAO \& FINUT. 2012. Fats and fatty acids in human nutrition. Report of an expert consultation, 91, 9-20.

27. Gil A, Martinez de Victoria E, Olza J: Indicators for the evaluation of diet quality. Nutr Hosp, 2015, 31(s3):128-144.

28. Jimenez JFL, Cervera MM, Blesa MAL: Guidelines for specialized nutritional and metabolic support in the critically-ill patient: update. Consensus SEMICYUC-SENPE: cardiac patient. Nutr Hosp, 2011, 26(s2):76-80.

29. Czyż K, Bodkowski R, Herbinger G, Librowski T: Omega-3 Fatty acids and their role in central nervous system-A Review. Curr Med Chem, 2016, 23:816-831.

30. CODEX STAN 243-2003. Norma del Codex para leches fermentadas. http://www.salud.gob.mx/unidades/cdi/nom/111ssa14.html Accesed in 07/08/2016

31. Carvalho A, Silva J, Ho P, Teixeira P, Malcata F, Gibbs P: Relevant factors for the preparation of freezedried lactic acid bacteria. Int Dairy J, 2004, 14:835-847.

32. Capela P, Hay T, Shah N: Effect of cryoprotectants, prebiotics and microencapsulation on survival of probiotic organisms in yogurt and freeze-dried yogurt. Food Res Int, 2006, 39:203-211.

33. Ducluzeau R, Bensaada M: Comparative effect of a single or continuous administration of "Saccharomyces boulardii" on the establishment of various strains of" candida" in the digestive tract of gnotobiotic mice. Ann Microbiol, 1982, 133:491-501.

34. Ronka E, Malinen E, Saarela M, Rinta K, Aarnikunnas J, Palva A: Probiotic and milk 

technological properties of Lactobacillus brevis. Int J Food Microbiol, 2003, 83:63-74.

35. Verstrepen KJ, Klis FM: Floculation, adhesión and biofilm formation in yeasts. Mol Microbiol, 2006, 60:5-15.

36. Rajkowska K, Kunicka-Styczyńska A: Phenotypic and genotypic characterization of probiotic yeasts. Biotechnol Biotechnol Equip, 2009, 23(1):662-665. 